\title{
A METHOD FOR RELIABILITY ASSESSMENT OF STRUCTURAL COMPONENTS OF AIRCRAFT AND SEA-GOING SHIPS WITH TAKING INTO ACCOUNT A GIVEN FAILURE GENERATION MODEL
}

\author{
Henryk Tomaszek, Prof. \\ Mariusz Zieja, Ph. D. \\ Mariusz Ważny, Ph. D. \\ Air Force Institute of Technology, Poland
}

\begin{abstract}
This paper presents a metod for reliability assessment of structural components on the basis of diagnostic parameters recorded during operation of aircraft and sea going ships. It was assumed that a potential failure may simultaneously concerns surface wear process and fracture of an arbitrary structural component. In order to develop a reliability assessment model some elements of random walk theory were applied. This work covers surface wear density functions of a component. In the case of surface wear the model is based on a difference equation from which, after transformation, a Fokker-Planck partial differential equation was obtained. By solving the equation component's surface wear density function is achieved.

In the second part of the work a generalization of the model was made by introducing to it probability of disastrous fracture of a component. As a result, a generalized Fokkera-Planck's equation was obtained. By making use of the equation, was obtained a relationship for assessment of reliability of a structural component in case when failure occurs due to surface wear with taking into account possible fracture of the component. In the end a numerical example which shows practical application of the developed method, is attached.
\end{abstract}

Keywords: bearing capacity factor, displacement, compression, tension, depth factor

\section{INTRODUCTION}

Assessment of reliability of structural components during operation of sea-going ships and aircraft is associated with prediction of their technical state. Such assessment is usually described by diagnostic parameters. A change in technical state is connected with change in values of diagnostic parameters $[4,6,12,22]$. Character of the loading of the structural components in the form of destructive processes causes changes in values of diagnostic parameters.

Wear, fatigue, corrosion, erosion and ageing processes have a decisive impact on changes in values of diagnostic parameters of mechanical components. The processes lead to changing the characteristics of structural components: geometrical,physical, strength etc $[10,18,19,21]$. Recognition of physics and analytical description of consequences of action of destructive processes is connected with many difficulties due to complexity of the problems associated with the considered issue. To ease description of consequences of action of destructive processes many different simplified mathematical models are often used $[2,5,7,8,9,16,17]$.
This work is aimed at assessing reliability of a structural component subjected to wear processes in the form of loss in mass and changes in geometrical dimensions of the component which is additionaly subjected to structural loads.

To assess reliability of structural component some elements of random walk theory were used.

The following assumptions are taken into account:

- Technical state of a structural component is determined by a single dominating diagnostic parameter "Z" in the form of the deviation from its nominal value :

where:

$$
z=\left|\mathrm{X}-\mathrm{X}^{n o m}\right|
$$

$\mathrm{X}$ - current value of diagnostic parameter,

$\mathrm{X}^{\text {nom }}$ - nominal value of diagnostic parameter.

- Load upon the component is of a pulse mode. Load impulses acting onto ship propulsion shafts or components of aircraft landing gear during landing operation, may serve as its example. 
- $\quad$ Change in diagnostic parameter value takes place first of all during operation of sea-going ship or aircraft.

- The parameter „Z” is non-decreasing.

- Value of deviation of the diagnostic parameter „z" determines a state of structural component reliability. If it is contained within the range $\mathrm{z} \in\left[0, \mathrm{z}_{\mathrm{d}}\right]$ then it will be taken as fit for use. Otherwise it will be considered unfit for use.

- Measuring the diagnostic parameter deviation is made in a discrete system with the step $h$, where:

$$
h=\frac{\mathrm{X}_{\text {nom }}}{\hat{k}}
$$

and, $\hat{k}$ is appropriately selected.

- Deviation of the diagnostic parameter takes discrete values in the form:

$$
z_{k}=k h \text {, }
$$

where $\mathrm{k}=0,1,2, \ldots$

- Schematic diagram of changes in values of the diagnostic parameter deviation along the time is presented in Fig. 1.

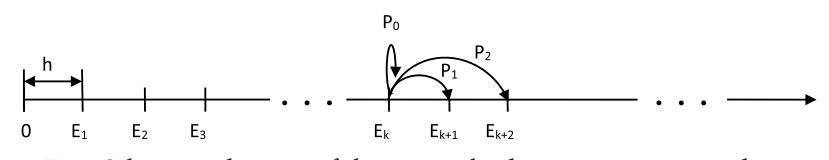

Fig.1 Schematic diagram of changes in the diagnostic parameter deviation

where:

$\mathrm{E}_{\mathrm{k}}$ - component's state $(\mathrm{k}=0,1,2, \ldots)$,

$\mathrm{P}_{\mathrm{i}}$ - occurrence probability of a change in component's state.

\section{DETERMINATION OF WEAR DENSITY FUNCTION FOR STRUCTURAL COMPONENT OF SEA-GOING SHIP OR AIRCRAFT}

As assumed in this work, the wearing of a mechanical device component is manifested by a loss in its mass and change in its linear dimensions. It was also assumed that the component is loaded, during operation, by random short-term impulses whose number, depending on time, is described by a process with the rate $\lambda$ :

$$
\lambda=\frac{P}{\Delta t}
$$

where:

$\mathrm{P}$ - probability of using the component within the time interval $\Delta \mathrm{t}$,

$\Delta \mathrm{t}$ - time interval in which a load impulse occurs.

The impulse rate may be considered to be intensity of aircraft flights or sea-going ship voyages.
It can be assumed that:

$$
(1-\lambda \Delta t)+\lambda \Delta t \approx 1
$$

As a result of action of load impulses a discrete increase in values of wear takes place (it randomly occurs after the states $\mathrm{E}_{0}, \mathrm{E}_{1}, \mathrm{E}_{2}, \ldots, \mathrm{E}_{\mathrm{k}}, \ldots$.).

It is assumed that a single impulse can cause an increase of wear with an appropriate probability of occurrence, as follows:

0 - with the probability $\mathrm{P}_{0}$;

h - with the probability $\mathrm{P}_{1}$;

$2 \mathrm{~h} \quad$ - with the probability $\mathrm{P}_{2}$.

If other possibilities are very low probable, then:

$$
P_{0}+P_{1}+P_{2} \cong 1
$$

Let $U_{k, t}$ means probability of the event that in the instant $t$ deviation of diagnostic parameter reaches the state $k$. On the basis of these assumptions a difference equation which characterizes a way of growing the parameter deviation can be written [15] as follows :

$U_{k, t+\Delta t}=(1-\lambda \Delta t) U_{k, t}+\lambda \Delta t P_{0} U_{k, t}+\lambda \Delta t P_{1} U_{k-1, t}+\lambda \Delta t P_{2} U_{k-2, t}$

where:

$$
(1-\lambda \Delta t)+\lambda \Delta t P_{0}+\lambda \Delta t P_{1}+\lambda \Delta t P_{2} \approx 1
$$

In functional description Eq. (7) takes the following form :

$u(z, t+\Delta t)=(1-\lambda \Delta t) u(z, t)+\lambda \Delta t P_{0} u(z, t)+\lambda \Delta t P_{1} u(z-h, t)+\lambda \Delta t P_{2} u(z-2 h, t)$

The difference equation (9) can be transformed into a partial differential equation by using the following approximation [14]:

$$
\left.\begin{array}{l}
u(z, t+\Delta t) \cong u(z, t)+\frac{\partial u(z, t)}{\partial t} \Delta t \\
u(z-h, t) \cong u(z, t)-\frac{\partial u(z, t)}{\partial z} h+\frac{1}{2} \frac{\partial^{2} u(z, t)}{\partial z^{2}} h^{2} ; \\
u(z-2 h, t)=u(z, t)-\frac{\partial u(z, t)}{\partial z} 2 h+\frac{1}{2}(2 h)^{2} \frac{\partial^{2} u(z, t)}{\partial z^{2}} ;
\end{array}\right\}
$$

On substitution of the approximation (10) into Eq. (9) the following is obtained:

$\frac{\partial u(z, t)}{\partial t}=-\lambda\left(P_{1} h+P_{2} 2 h\right) \frac{\partial u(z, t)}{\partial z}+\frac{1}{2} \lambda\left(P_{1} h^{2}+P_{2}(2 h)^{2}\right) \frac{\partial^{2} u(z, t)}{\partial z_{(11)}^{2}}$

On taking the notation:

$$
\begin{gathered}
b=P_{1} h+P_{2} 2 h \\
a=P_{1} h^{2}+P_{2}(2 h)^{2}
\end{gathered}
$$

the following can be written : 


$$
\frac{\partial u(z, t)}{\partial t}=-\lambda b \frac{\partial u(z, t)}{\partial z}+\frac{1}{2} \lambda a \frac{\partial^{2} u(z, t)}{\partial z^{2}}
$$

Eq. (7) has the form of Fokker-Planck equation.

A particular solution of Eq. (13) is searched, namely such one that fulfils the following conditions: when $t \rightarrow 0$, the solution converges to Dirac function, i.e. $\mathrm{u}(\mathrm{z}, \mathrm{t}) \rightarrow 0$ for $\mathrm{z} \neq 0$ and $\mathrm{u}(0, \mathrm{t}) \rightarrow+\infty$, but in the way that integral of the function $\mathrm{u}$ is equal to one for all the instants $\mathrm{t}>0$.

The solution of Eq. (13) with the above given condition is of the following form [20]:

$$
u(z, t)=\frac{1}{\sqrt{2 \pi a \lambda t}} e^{-\frac{(z-b \lambda t)^{2}}{2 a \lambda t}}
$$

The relationship (8) is the searched probability density function of structural component wearing due to action of randomly occurring damaging impulses.

As the number of impulses (aircraft landings) is described by the relation:

$$
\mathrm{N}=\lambda \mathrm{t}
$$

then the wear density function of structural component can be written in the form:

$$
L=u\left(N_{0}, z_{0} ; b, a\right) \prod_{k=0}^{n-1} u\left(N_{k}, z_{k}, N_{k+1}, z_{k+1} ; b, a\right)
$$

where:

$\mathrm{bN}$ - expected value of diagnostic parameter deviation in the instant $t$ when the number of impulses equals $\mathrm{N}$;

aN - variance value of diagnostic parameter deviation up to the instant $\mathrm{t}$ when the number of impulses equals $\mathrm{N}$.

In order to be able to make use of the density function (16) the parameters b and a should be first estimated. Data necessary to use Eqs. (12) not always are available. Another way to estimate the parameters is to apply the likelihood function which is represented by the following product $[3,14]$ :

$$
L=u\left(N_{0}, z_{0} ; b, a\right) \prod_{k=0}^{n-1} u\left(N_{k}, z_{k}, N_{k+1}, z_{k+1} ; b, a\right)
$$

where:

$\left(\mathrm{z}_{0}, \mathrm{z}_{1}, \mathrm{z}_{3}, \ldots, \mathrm{z}_{\mathrm{n}}\right)$ stand for observed values of diagnostic parameter deviation from nominal value, for the numbers of load cycles $\left(\mathrm{N}_{0}, \mathrm{~N}_{1}, \mathrm{~N}_{3}, \ldots, \mathrm{N}_{\mathrm{n}}\right)$, respectively.

Estimation of the unknown parameters $b$ and $a$ is obtained by solving the following set of equations:

$$
\left.\begin{array}{l}
\frac{\partial \log L}{\partial b}=0 \\
\frac{\partial \log L}{\partial a}=0
\end{array}\right\}
$$
following form:

The appropriate calculation formulae achieve the

$$
\begin{gathered}
b^{*}=\frac{z_{n}}{N_{n}} \\
a *=\frac{1}{n} \sum_{k=0}^{n-1} \frac{\left[\left(z_{k+1}-z_{k}\right)-b *\left(N_{k+1}-N_{k}\right)\right]^{2}}{\left(N_{k+1}-N_{k}\right)}
\end{gathered}
$$

Having estimated the parameters $b^{\star}$ and $a^{\star}$ one can write the formula for device component reliability:

$$
R(N)=\int_{-\infty}^{z_{d}} u(z, N) d z
$$

where:

$\mathrm{u}(\mathrm{z}, \mathrm{N})$ - determined from Eq. (16)

$z_{d}$ - permissible value of diagnostic parameter deviation.

\section{A MODEL OF THE WEARING OF STRUCTURAL COMPONENT OF SEA- GOING SHIP OR AIRCRAFT WITH TAKING INTO ACCOUNT POSSIBILITY OF ITS SUDDEN DAMAGE (FRACTURE)}

It is assumed that load applied to structral component produces its surface wear and simultaneously reaches such value that the component may suffer sudden damage (fracture occurs). Such possibility may be illustrated by the case of work of tyre of airplane during its hard landing.

Let:

$\sum$ - stand for random variable of immediate strength of structural component, of the density function $\mathrm{g}_{1}(\sigma)$,

$\mathrm{W}$ - stand for random variable of stress resulting from load impulse of the density function (Fig. 2).

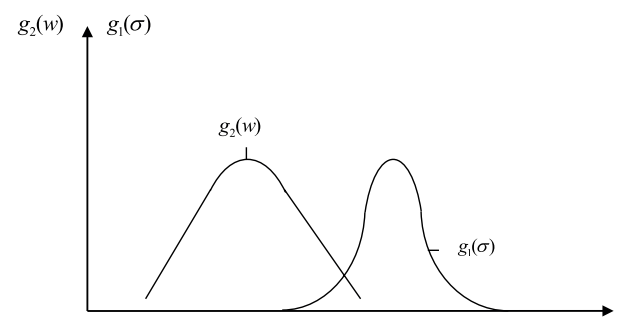

Fig. 2. Schematic diagram of load applied to the structural component of seagoing ship or aircraft 
Immediate damage will take place when :

$$
\mathrm{W}-\sigma>0
$$

where:

$\mathrm{w}$ and $\sigma$ are realizations of the random variables $\mathrm{W}$ and $\Sigma$. Therefore :

$$
\aleph=W-\sum
$$

The density function of the random variable $\aleph$ can be determined from the relation:

$$
f(\aleph)=\int_{C_{1}}^{C_{2}} g_{1}(w-\aleph) g_{2}(w) d w
$$

where:

$\mathrm{C}_{1}, \mathrm{C}_{2}$ - limit values of stresses due to action of load impulse.

Occurrence probability of damage of structural component is as follows :

$$
P_{w}=\lambda \Delta t Q
$$

where:

$$
Q=P\{W-\Sigma>0\}=\int_{0}^{\infty} f(\aleph) d \aleph
$$

The events which occur during wearing process and sudden damage, sum up to one.

Therefore,

$$
(1-\lambda \Delta t)+\lambda \Delta t P_{0}(1-Q)+\lambda \Delta t P_{1}(1-Q)+\lambda \Delta t P_{2}(1-Q)+\lambda \Delta t Q \cong 1
$$

Let $\mathrm{U}_{\mathrm{z}, \mathrm{t}}$ stand for probability of the event that in the instant "t" the component wear deviation is equal to „, $\mathrm{z}$ ". By making use of Eq. (27) the following difference equation can be written:

$$
\begin{aligned}
U_{z, t+\Delta t}=(1-\lambda \Delta t) U_{z, t} & +\lambda \Delta t P_{0}(1-Q) U_{z, t}+\lambda \Delta t P_{1}(1-Q) U_{z-h, t}+ \\
& +\lambda \Delta t P_{2}(1-Q) U_{z-2 h, t}
\end{aligned}
$$

In functional description Eq. (28) takes the following form: $u(z, t+\Delta t)=(1-\lambda \Delta t) u(z, t)+\lambda \Delta t P_{0}(1-Q) u(z, t)+\lambda \Delta t P_{1}(1-Q) u(z-h, t)+$ $+\lambda \Delta t P_{2}(1-Q) u(z-2 h, t)$

By taking into account the relations (10) Eq. (29) can be transformed to the form :

$$
\begin{gathered}
u(z, t)+\frac{\partial u(z, t)}{\partial t} \Delta t=(1-\lambda \Delta t) u(z, t)+\lambda \Delta t P_{0}(1-Q) u(z, t)+ \\
+\lambda \Delta t P_{1}(1-Q)\left(u(z, t)-h \frac{\partial u(z, t)}{\partial z}+\frac{1}{2} h^{2} \frac{\partial^{2} u(z, t)}{\partial z^{2}}\right)+ \\
+\lambda \Delta t P_{2}(1-Q)\left(u(z, t)-2 h \frac{\partial u(z, t)}{\partial z}+\frac{1}{2}(2 h)^{2} \frac{\partial^{2} u(z, t)}{\partial z^{2}}\right)
\end{gathered}
$$

Therefore:

$$
\begin{aligned}
u(z, t)+\frac{\partial u(z, t)}{\partial t} \Delta t & =\left[(1-\lambda \Delta t)+\lambda \Delta t P_{0}(1-Q)+\lambda \Delta t P_{1}(1-Q)+\lambda \Delta t P_{2}(1-Q)\right] u(z, t)+ \\
& +\left[\lambda \Delta t P_{1}(1-Q) h+\lambda \Delta t P_{2}(1-Q) 2 h\right] \frac{\partial u(z, t)}{\partial z}+ \\
+ & \frac{1}{2}\left[\lambda \Delta t P_{1}(1-Q) h^{2}+\lambda \Delta t P_{2}(1-Q)(2 h)^{2}\right] \frac{\partial^{2} u(z, t)}{\partial z^{2}}
\end{aligned}
$$

Now, $\mathrm{u}(\mathrm{z}, \mathrm{t})$ is added to and distracted from the right hand side of Eq. (31). Instead of one at $(-\mathrm{u}(\mathrm{z}, \mathrm{t}))$, the relation (27) is substituted. On simplification the following is obtained:

$$
\begin{aligned}
\frac{\partial u(z, t)}{\partial t} \Delta t & =-\lambda \Delta t Q u(z, t)-\left[\lambda \Delta t P_{1}(1-Q) h+\lambda \Delta t P_{2}(1-Q) 2 h\right] \frac{\partial u(z, t)}{\partial z}+ \\
& +\frac{1}{2}\left[\lambda \Delta t P_{1}(1-Q) h^{2}+\lambda \Delta t P_{2}(1-Q)(2 h)^{2}\right] \frac{\partial^{2} u(z, t)}{\partial z^{2}}
\end{aligned}
$$

Dividing by $\Delta$ t one obtains:

$$
\begin{aligned}
\frac{\partial u(z, t)}{\partial t} & =-\lambda Q u(z, t)-\left(\lambda P_{1}(1-Q) h+\lambda P_{2}(1-Q) 2 h\right) \frac{\partial u(z, t)}{\partial z}+ \\
& +\frac{1}{2}\left(\lambda P_{1}(1-Q) h^{2}+\lambda P_{2}(1-Q)(2 h)^{2}\right) \frac{\partial^{2} u(z, t)}{\partial z^{2}}
\end{aligned}
$$

By substituting the notations:

$$
\begin{gathered}
c=\lambda Q \\
\hat{b}=\lambda(1-Q)\left(P_{1} h+P_{2} \cdot 2 h\right)=\lambda(1-Q) b \\
\hat{a}=\lambda(1-Q)\left(P_{1} h^{2}+P_{2}(2 h)^{2}\right)=\lambda(1-Q) a
\end{gathered}
$$

the following equation is finally achieved:

$$
\frac{\partial u(z, t)}{\partial z}=-c u(z, t)-\hat{b} \frac{\partial u(z, t)}{\partial z}+\frac{1}{2} \hat{a} \frac{\partial^{2} u(z, t)}{\partial z^{2}}
$$

Eq. (35) is more general than Fokker-Planck equation. Like in the case of Fokker-Planck equation, is searched a particular solution which fulfils the following conditions:

when $t \rightarrow 0$ the solution converges to Dirac's function, i.e. $\mathrm{u}(\mathrm{z}, \mathrm{t}) \rightarrow 0$ for $\mathrm{z} \neq 0$ and $\mathrm{u}(0, \mathrm{t}) \rightarrow+\infty$, but in such way that integral of the term of the function which contains $\mathrm{z}$ is equal to one for all $t>0$.

The solution of Fokker-Planck equation (i.e. that without the term "-cu( $\mathrm{z}, \mathrm{t})$ "), for the above specified condition, has the following form [15]:

$$
\bar{u}(z, t)=\frac{1}{\sqrt{2 \pi \lambda(1-Q) a t}} e^{-\frac{(z-\lambda(1-Q) b t)^{2}}{2 \lambda(1-Q) a t}}
$$

or

$$
\bar{u}(z, N)=\frac{1}{\sqrt{2 \pi(1-Q) a N}} e^{-\frac{(z-(1-Q) b N)^{2}}{2(1-Q) a N}}
$$

Hence the solution of Eq. (35) will achieve the following form [15]: 


$$
u(z, t)=e^{-c t} \bar{u}(z, t)
$$

In order to prove that the above given relation is just the searched solution of Eq. (35) the following transformation can be offerred:

$$
\begin{gathered}
\frac{\partial u(z, t)}{\partial t}=-c e^{-c t} \bar{u}(z, t)+e^{-c t} \frac{\partial \bar{u}(z, t)}{\partial t}= \\
=-c u(z, t)+e^{-c t}\left(-\hat{b} \frac{\partial \bar{u}(z, t)}{\partial z}+\frac{1}{2} \hat{a} \frac{\partial^{2} \bar{u}(z, t)}{\partial z^{2}}\right)= \\
\left.=-c u(z, t)-\hat{b} \frac{\partial u(z, t)}{\partial z}+\frac{1}{2} \hat{a} \frac{\partial^{2} u(z, t)}{\partial z^{2}}\right)
\end{gathered}
$$

The following density function is the solution of Eq. (35) :

$$
u(z, t)=\lambda e^{-\lambda t} \bar{u}(z, t)
$$

where:

$$
\int_{0}^{\infty} \int_{-\infty}^{\infty} \lambda e^{-\lambda t} \bar{u}(z, t) d z d t=1
$$

The presented transformation (39) is also valid in case it is applied to the relation (40).

\section{ASSESSMENT OF STRUCTURAL \\ COMPONENT RELIABILITY IN \\ THE ASPECT OF WEAR WITH SIMULTANEOUSLY POSSIBLE SUDDEN DAMAGE}

Causes of structural component failures in the form of wear and disastrous fracture, in the sense of reliability, form a series structure. It can be assumed that a structural component is built from "two components". One is subjected to wear and the other is put under structural load. The system is in serviceable state when all its components are in serviceable state, and the system is in non-serviceable state when at least one of its components is damaged.

Hence the reliability of structural component of sea-going ship or aircraft is described by the relation as follows $[1,11,13]$ :

$$
R(t)=R_{1}(t) R_{2}(t)
$$

where:

$$
\begin{gathered}
R_{1}(t)=e^{-c t} \\
R_{2}(t)=\int_{-\infty}^{z_{d}} \bar{u}(z, t) d z
\end{gathered}
$$

$\mathrm{z}_{\mathrm{d}}$ - value of diagnostic parameter deviation permissible for safety reasons, $\bar{u}(z, t)$ - density function of the deviation, determined by the relation (36) or (37).

Eq. (41) can be written in the form:

$$
R(t)=e^{-c t} \int_{-\infty}^{z_{d}} \bar{u}(z, t) d z
$$

where:

$$
\bar{u}(z, t)=\frac{1}{\sqrt{2 \pi \lambda(1-Q) \Delta t}} e^{-\frac{(z-(1-Q) b \lambda t)^{2}}{2(1-Q) a \lambda t}}
$$

And, unserviceability of an component is:

$$
\hat{Q}(t)=1-e^{-c t} \int_{-\infty}^{z_{d}} \bar{u}(z, t) d z
$$

Density function of failures can be determined in the following way:

$$
f(t)=\frac{\partial}{\partial t} \hat{Q}(t)
$$

Hence:

$$
\begin{gathered}
f(t)=-\left[\left(-c e^{-c t} \int_{-\infty}^{z_{d}} \bar{u}(z, t) d z\right)+e^{-c t} \frac{d}{d t} \int_{-\infty}^{z_{d}} \bar{u}(z, t) d z\right] \\
f(t)=c e^{-c t} \int_{-\infty}^{z_{d}} \bar{u}(z, t) d z-e^{-c t} \frac{d}{d t}\left(1-\int_{z_{d}}^{\infty} \bar{u}(z, t) d z\right) \\
f(t)=c e^{-c t} \int_{-\infty}^{z_{d}} \bar{u}(z, t) d z+e^{-c t} \frac{d}{d t} \int_{z_{d}}^{\infty} \bar{u}(z, t) d z
\end{gathered}
$$

Making use of the work [20] one can write the following:

$\frac{d}{d t} \int_{z_{d}}^{\infty} \bar{u}(z, t) d z=\frac{z_{d}+(1-Q) b \lambda t}{2 t} \frac{1}{\sqrt{2 \pi(1-Q) a \lambda t}} e^{-\frac{(z d-(1-Q) b \lambda t)^{2}}{2(1-Q) a \lambda t}}$

Therefore it can be written :

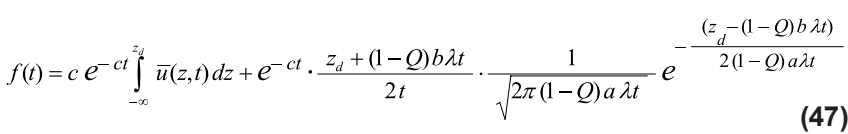

On the basis of the determined reliability and density function for structural component its failure rate can be determined as follows:

$$
\chi(t)=\frac{f(t)}{R(t)}
$$

where: $f(t)$ - as described by Eq. (45) and R(t) - as described by Eq. (42). 
Making use of the failure rate according to Eq. (48) one can write the following formula for the reliability of a structural component of aircraft or sea going ship in the assumed failure generation conditions, as follows:

$$
R(t)=e^{-\int_{0}^{t} \chi(w) d w}
$$

\section{A NUMERICAL EXAMPLE OF RELIABILITY ASSESSMENT}

In the below presented example a fragment of an aircraft tyre ( Fig. 3) was taken into consideration. In the process of operation wear of yre tread takes place during starts and landings of airplane. Aircraft tyre is also subjected to structural loads and during hard landing it may undergo sudden damage.
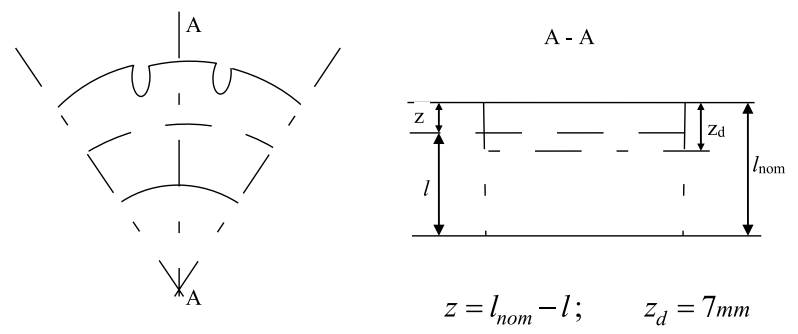

Fig. 3. Cross-section of a tyre fragment

$1_{\text {nom }}$ - nominal thickness of tyre tread,

1 - current thickness of tyre tread,

$\mathrm{z}$ - current wear of tyre tread,

$\mathrm{z}_{\mathrm{d}}$ - permissible wear of tyre tread.

For the assessment of aircraft tyre reliability Eq. (42) was applied:

$R(N) \cong e^{-Q N} \int_{-\infty}^{z_{d}} \frac{1}{\sqrt{2 \pi(1-Q) a N}} e^{-\frac{(z-(1-Q) b N)^{2}}{2(1-Q) a N}} d z$

Hence, after normalization :

$$
R(N)=e^{-Q N} \cdot \frac{1}{\sqrt{2 \pi}} \int_{-\infty}^{\frac{\left(z_{d}-(1-Q) b N\right.}{\sqrt{(1-Q) a N}}} e^{-\frac{\chi^{2}}{2}} d x
$$

For the reliability assessment in accordance with Eq. (50) the following data were selected [20]:

$$
\begin{aligned}
& \mathrm{b}=0,0166 \\
& \mathrm{a}=0,00051 \\
& \mathrm{Q}=0,00001 \\
& \mathrm{z}_{\mathrm{d}}=7 \mathrm{~mm}
\end{aligned}
$$

Tab. 1 and Fig. 4. present results of the calculations performed with the use of the following relations:

$$
\beta(N)=\frac{z_{d}-(1-Q) b N}{\sqrt{(1-Q) a N}}
$$

\begin{tabular}{|c|c|c|c|c|c|c|c|c|c|c|c|}
\hline$\overline{\mathbf{N}}$ & 20 & $\overline{550}$ & $\begin{array}{l}100 \\
\end{array}$ & 150 & 200 & 250 & 300 & 350 & $\begin{array}{l}400 \\
\end{array}$ & $4 \overline{450}$ & $\overline{500}$ \\
\hline$\beta(N)$ & 66,023 & 38,638 & 23,646 & 16,306 & 11,523 & 7,982 & 5,164 & 2,817 & 0,797 & $-0,981$ & $-2,574$ \\
\hline$R_{2}(N)$ & 1 & 1 & 1 & 1 & 1 & 1 & 1 & 0,998 & 0,787 & 0,163 & 0,005 \\
\hline$R_{1}(N)$ & 1 & 1 & 0,999 & 0,999 & 0,998 & 0,998 & 0,997 & 0,997 & 0,996 & 0,996 & 0,995 \\
\hline$R(N)$ & 1 & 1 & 0,999 & 0,999 & 0,998 & 0,998 & 0,997 & 0,995 & 0,784 & 0,162 & 0,005 \\
\hline
\end{tabular}

$$
R_{1}(N)=e^{-Q N}
$$

$$
R_{2}(N)=\frac{1}{\sqrt{2 \pi}} \int_{-\infty}^{\beta(N)} e^{-\frac{\chi^{2}}{2}} d x
$$

Tab. 1. Reliability of the considered aircraft tyre

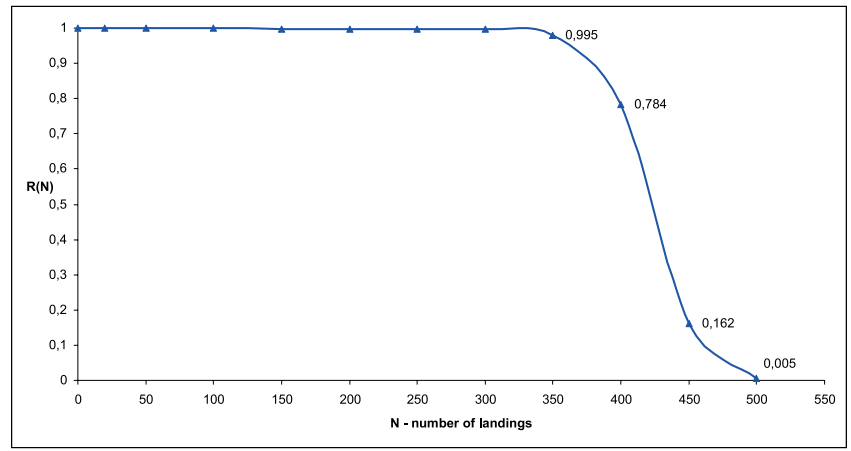

Fig. 4. Reliability of the considered aircraft tyre

\section{FINAL REMARKS}

The modelling of wear of structural components which are subjected to different modes of failure generation, requires to make use of test results acquired from operational processes of sea-going ships and aircraft. The more accurate and complete the results of tests of structral components in operation, the more precise and complex the developed formulae for assessment of their reliability. In this work relatively simple assumptions as to operational conditions of structural component, were accepted. It was assumed that wear and fatigue processes may take place simultaneously. Mechanisms of wear and destruction of structural components of sea-going ships and aircraft are complex as a result of complicated environment in which they operate. From the scientific point of view, are very interesting models which take additionally into account fatigue fracture processes occurring in structural components. The presented reliability assessment method with the use of random walk theory should be further perfected by taking into account more accurate models of wear and fatigue processes occurring in structural components. 


\section{BIBLIOGRAPHY}

1. Baranowski P., Małachowski J.: Numerical study of selected military vehicle chassis subjected to blast loading in terms of tyre strength improving. Bulletin of The Polish Academy of Sciences: Technical Sciences. Vol. 63, No 4, 2015, pp. $867-878$.

2. Casciati F., Roberts B.: Mathematical Models for Structural Reliability Analysis. Boca Raton/New York/London/Tokyo: CRC Press, 1996.

3. DeLurgio SA.: Forecasting principles and applications. University of Missouri-Kansas City. Irwin/McGraw-Hill, 1998.

4. Dhillon BS.: Design Reliability. Fundamentals and Applications. Ottawa: Boca Raton/New York/London/ Washington: CRC Press 1999.

5. Girtler J., Ślęzak M.: Four-state stochastic model of changes in the reliability states of a motor vehicle. Eksploatacja $i$ Niezawodnosc - Maintenance and Reliability. Vol. 15, No 2, 2013, pp. $156-160$.

6. Girtler J.: Identification of damages of tribological associations in crankshaft and piston systems of two-stroke internal combustion engines used as main propulsion in sea-going vessels and proposal of probabilistic description of loads as causes of these damages. Polish Maritime Research. Vol. 22, No 2, 2015, pp. 44 - 54.

7. Girtler J.: The semi-Markov model of the process of appearance of sea-going ship propulsion system ability and inability states in application to determining the reliability of these systems. Polish Maritime Research. Vol. 20, No 4(80), 2013, pp. $18-24$.

8. Grabski F.: Semi-Markov failure rates processes. Applied mathematics and computation. Vol. 217, No 24, 2011, pp. 9956-9965.

9. Gucma S., Slaczka W.: Methods for optimization of sea waterway systems and their application. Polish Maritime Research. Vol. 22, No 3, 2015, pp. 14 - 19.

10. Idziaszek Z., Grzesik N.: Object characteristics deterioration effect on task realizability - outline method of estimation and prognosis. Eksploatacja i Niezawodnosc - Maintenance and Reliability. Vol. 16, No 3, 2014, pp. 433-440.

11. Jodejko-Pietruczuk A., Werbinska-Wojciechowska S.: Analysis of maintenance models' parameters estimation for technical systems with delay time. Eksploatacja i Niezawodnosc - Maintenance and Reliability. Vol. 16, No 2, 2014, pp. 288-294.
12. Korczewski Z. Analysing the potential for application of the phase shift method in endoscopic examination of marine engines. Polish Maritime Research. Vol. 20, No 1, 2013, pp. $23-30$.

13. Nowakowski T., Tubis A., Werbinska-Wojciechowska S.: Maintenance Decision Making Process - A Case Study of Passenger Transportation Company. Theory and engineering of complex systems and dependability. Advances in Intelligent Systems and Computing. Proceedings of the Tenth International Conference on Dependability and Complex Systems DepCoSRELCOMEX. Vol. 365, 2015, pp. 305-318.

14. Pham H.: Handbook of Engineering Statistics. London: Springer-Verlag 2006.

15. Risken H.: The Fokker-Planck Equation. Methods of Solution and Applications. Springer Verlag, 1984.

16. Rudnicki J.: Application isssues of the semi-markov reliability model. Polish Maritime Research. Vol. 22, No 1,2015 , pp. $55-64$.

17. Rudnicki J.: The time of the first transition of the semiMarkov process in the evaluation of diesel engine operation. Combustion Engines. Vol. 145, No 2, 2011 (145), pp. 89-98.

18. Tomaszek H., Jasztal M., Zieja M.: A simplified method to assess fatigue life of selected structural components of an aircraft for a variable load spectrum. Eksploatacja i Niezawodnosc - Maintenance and Reliability 2011; 4: 29-34.

19. Tomaszek H., Jasztal M., Zieja M.: Application of the Paris formula with $\mathrm{m}=2$ and the variable load spectrum to a simplified method for evaluation of reliability and fatigue life demonstrated by aircraft components. Eksploatacja i Niezawodnosc - Maintenance and Reliability 2013; 15(4): 297-304.

20. Tomaszek H., Żurek J., Jasztal M.: Prediction of failures endangering safety of aircraft operation ( in Polish ). Wydawnictwo Naukowe Instytutu Technologii Eksploatacji, Warszawa 2008.

21. Woch M., Kurdelski M., Matyjewski M.: Reliability at the checkpoints of an aircraft supporting structure. Eksploatacja i Niezawodnosc - Maintenance and Reliability. Vol. 17, No 3, 2015, pp. 457 - 462.

22. Żurek J., Tomaszek H., Zieja M.: Analysis of structural component's lifetime distribution considered from the aspect of the wearing with the characteristic function applied. Safety, Reliability and Risk Analysis: Beyond the Horizon. CRC Press/Balkema, Taylor \& Francis Group, 2014: p. 2597-2602. 
CONTACT WITH THE AUTHORS:

Henryk Tomaszek Instytut Techniczny Wojsk Lotniczych

ul. Księcia Bolesława 6

01-494 Warszawa

Polska

e-mail:poczta@itwl.pl

\author{
Mariusz Zieja \\ Instytut Techniczny Wojsk Lotniczych \\ ul. Księcia Bolesława 6 \\ 01-494 Warszawa \\ Polska \\ e-mail: mariusz.zieja@itwl.pl \\ Mariusz Ważny \\ Instytut Techniki Lotniczej \\ Wojskowa Akademia Techniczna \\ ul. Kaliskiego 2 \\ 00-908 Warszawa \\ Polska \\ e-mail: mwazny@wat.edu.pl
}

